\title{
Analysis on the Monetization of Sales Channels Under the Frame of Farmer Professional Cooperatives - Taking 35 Professional Grape Cooperatives in Jinxiang, Shandong Province as an Example
}

\author{
Zhou Teng ${ }^{1, a}$, Liu Yao yao ${ }^{2, b^{*}}$ \\ ${ }^{1}$ School of Economics and Management of XI'an Mingde Institute of Technology, Xi'an, Shaanxi, China \\ ${ }^{2}$ School of Economics and Management of XI'an Mingde Institute of Technology, Xi'an, Shaanxi, China \\ a342588821@qq.com \\ b*674949659@qq.com
}

\begin{abstract}
As one of the new agricultural management systems, the original intention of the establishment of farmer cooperatives is to solve the problems of individual farmer's weakness in the market and the mismatch between income and risktaking, and to enhance the farmers' competitive position and bargaining power in the market. However, the transfer of market risk from farmers to cooperatives is not equivalent to the disappearance of market risk. From the perspective of risk, the essence is the process of transferring the risk from a single farmer to a farmer's professional cooperative, so as to achieve the effect of reporting the group to warm up in the face of risks. How to realize the thrilling leap from agricultural products to commodities and how to realize the transformation of materialized labor into general equivalent currency is still the primary problem faced by cooperatives, and it is also the core cohesion. The monetization of sales channels, on the one hand, realizes the circulation and redistribution of different resource endowments among members of the cooperative. On the other hand, through this incentive-compatible incentive mechanism, the overall welfare of the cooperative is improved and the market risk faced by the cooperative is reduced. In the long-term institutional arrangement, the focus should be on building an incentive and compatible mechanism for "honour replacement material".
\end{abstract}

Keywords: Farmer professional cooperatives, market risk, monetization of sales channels, incentive compatibility mechanism

\section{农民专业合作社框架下销售渠道货币化现象分析 一以山东省金乡县 35 家葡萄专业合作社为例}

\author{
周腾 $1, \mathrm{a}$ 刘遥遥 $2, \mathrm{~b}^{*}$
}

${ }^{1}$ 西安明德理工学院经济与管理学院, 西安, 陕西, 中国

2 西安明德理工学院经济与管理学院, 西安, 陕西, 中国

a342588821@qq.com

b*674949659@qq.com

摘要：农民专业合作社作为新型农业经营体系之一，其设立的初衷是要解决单个农户在市场中势单力薄、收益 与风险承担不匹配的问题, 提升农户在市场中的竞争地位与议价能力。然而，市场风险从农户向合作社的转移 并不等价于市场风险消失。从风险的角度观察，实质是有关风险从单个农户向农民专业合作社转移的过程，在 风险面前实现报团取暖的效果。如何实现农产品向商品的惊险跳跃，如何实现物化劳动向一般等价物货币的转 变, 依然是合作社面临的首要问题，也是其核心凝聚力所在。销售渠道的货币化，一方面实现了合作社内部成 
员不同资源禀赋的流转和再分配，另一方面通过这种激励相容的激励机制，增进合作社总体福利，降低了合作 社所面临的市场风险。在长期的制度安排中，应重点建设“荣誉置换物质（手续费）”的激励相容机制。

关键词：农民专业合作社；市场风险；销售渠道货币化；激励相容机制

\section{1.引言}

2014 年, 中央一号文件明确提出了新型农业经营 体系的构想，扶持发展新型农业经营主体，包括专业 大户、家庭农场、农民合作社、农业产业化龙头企业 等。在以上有力的制度供给保障下, 农民专业合作社 迅猛发展。作为一种嵌入农业与农村的制度安排, 合 作社设立的初衰是要解决单个农户在市场中势单力 薄、收益与风险承担不匹配的问题, 提升农户在市场 中的竞争地位与议价能力。

从风险的角度观察, 实质是有关风险从单个农户 向农民专业合作社转移的过程, 在风险面前实现报团 取暖的效果。如何实现农产品向商品的惊险跳跃, 如 何实现物化劳动向一般等价物货币的转变, 是合作社 面临的首要问题, 也是其核心凝聚力所在。这种不确 定性经常见诸报端, 以某类农产品大面积滞销为题, 我们称之为市场风险。

在农民专业合作社的理想愿景中，市场风险从农 户向合作社的转移并不等价于风险消失。由此, 合作 社作为参与主体所面临的市场风险问题, 也成为一个 新的课题。

\section{2.文献综述与简评}

徐健和汪旭晖 (2009) 认为, 订单农业增加了参 与农户的农业收入，降低了市场风险。但不同的农业 订单模式对收入的影响并不相同, 定价偏低、道德风 险与违约现象一直困扰着订单农业与合作社的发展。 田义文 (2010) 从法学视野的角度提出, 通过法律法 规和规章制度来规范农民专业合作社, 发挥后者组织 化、规模化、生产标准化和产品安全化的优势, 是化 解市场风险的有效路径。刘柯 (2013) 认为应创建农 民专业合作社自主品牌, 发展新型的直接销售模式, 降低交易成本和流通费用是避免市场风险的重要渠 道。陈江华 (2014) 通过实证方式发现, 30 岁以下社 员参与合作社订单农业的可能性较小, 而 51 岁-60 岁 的社员参与合作社订单农业的可能性较大, 并将其归 因于独立解决销售问题的能力差异。肖雅倩 (2018) 认为在新的农产品价格体制下,合作社面临的风险发 生了变化, 从单项指标看, 影响较大的是销售渠道、管 理能力和市场价格。通过品牌的维护和营销提高市场 竞争力, 降低市场风险。

梳理近十年来关于农民专业合作社市场风险化
解方式的有关文献可以清晰地发现, 主要分为内外两 种思路。对内强调农民专业合作社运行的规范化、利 益主体（管理层、社员）的激励相容性, 农产品的标 准化与质量化; 对外强调与销售渠道和消费群体的弹 性黏结, 包括订单农业、品牌塑造、媒介宣传等。

令人遗憾的是，在农民专业合作社并未掌控所有 销售渠道的现实下, 对内如何解决销售渠道丰富者与 销售渠道溃乏者之间的现实矛盾, 如何既保护了前者 的积极性又能实现销售渠道的流转与优化配置, 却少 有人提及与研究。

\section{3.研究方法}

本文的研究方法主要包括两种, 第一种是文献研 究法, 通过梳理近十年的有关文献, 整理农民专业合 作社市场风险问题的研究历史和现状, 掌握整体概貌 与前人已有的研究成果。第二种是调查法, 通过与葡 萄合作社管理层和社员的谈话、问答、实地了解等方 式，对调查搜集到的信息和资料进行分析、综合、归 纳和研究。

\section{4.市场风险分类与分析}

农民专业合作社市场风险是对合作组织、管理者、 参与农户影响最直接、最深刻、最敏感的风险。它也 是合作社形成与演进过程中最原始的催生动力之一。 市场风险可细分为有价无市, 有市低价, 无市无价, 有市有价四种情形。

\section{1 有价无市}

在有价无市的市场风险中，合作社与农户手中有 大量农产品, 同时农产品的价格也已经降到很低甚至 低于成本价, 但在有限的经济区域范围内, 仍表现为 严重的供需失衡, 生产相对过剩, 区域性饱和很容易 达到, 农产品找不到市场。

造成这种局面的因素很多, 其中主要的有: 自然 灾害方面, 持续恶劣天气导致农产品正常采摘、销售、 向外运输受阻, 农产品大量堆积, 短期供求严重失衡, 合作社无法有效连接市场; 基础设施方面, 由于地理 位置偏僻, 交通不便, 外向运输能力与运输渠道有限 导致合作社与外向市场连接不畅, 近距离市场趋于饱 和; 市场信息方面, 由于信息的不完全与不对称, 供 求双方无法同时获得所有的供求信息, 合作社与大市 
场的连接受阻甚至中断; 种植规模方面, 由于市场容 量有限，急速扩张的种植规模导致市场趋于饱和，对 于季节性明显, 集中上市的农产品无法完全被市场容 纳, 导致严重滞销。

\section{2 有市低价} 表现。

在有市低价的市场风险中，“谷贱伤农”是其集中

究其原因主要分为两个方面: 一是种植规模的过 剩导致供过于求，合作社与市场的连接之间没有摩擦 力，但价格很低; 二是由于突发事件导致的合作社与 市场之间的销售渠道受阻, 销售摩擦力増加, 造成供 需失衡, 例如: 客商的突然减少、黑恶势力垄断市场、 突发性自然灾害。

\section{3 无市无价}

无市无价的市场风险作为极端特例, 在现实中也 是存在的。被倾倒遗弃在路边的农产品或鼓励周围的 居民前往种植地免费采收农产品就是其外在表现形 式。

之所以出现这种严重伤害合作社与农户基本生 存利益的极端情况, 主要有如下原因: 首先, 由于对 农产品市场种植规模与市场容量信息获取不充分导 致农产品供给恶性膨胀; 其次, 替代性产品种类与供 给量增加, 可替代性增强; 再次, 农产品销售渠道出 现摩擦力导致销售空间严重萎缩甚至合作社农产品 与市场连接发生中断; 第四, 极端持续性自然灾害与 农产品遭受污染出现食用安全隐患。

\section{4 有市有价}

在健康繁荣的市场中, 买卖双方以相互可以接受 的均衡价格达成交易并被买出卖出, 此时的产品种植 规模、市场价格、替代性产品的价格与供给量处在均 衡状态。合作社与市场的销售渠道连接通畅, 此时没 有出现极端恶劣天气跟其他突发性系统事件的干扰, 这也是所有合作组织成立之初的宗旨与愿景。但现实 中由于信息不对称、不完全与销售摩擦力的存在，市 场往往会偏离这一理想状态，形成市场风险。

总结归纳以上分析, 农民专业合作社市场风险出 现的原因主要有三个方面: 一是由于合作社本身种植 规模的膨胀，替代性农产品的供给增加导致市场饱和， 供需失衡; 二是合作社与市场的连接不畅并出现销售 渠道摩擦力, 造成农产品的堆积; 三是由于极端恶劣 天气与突发性事件改变了供需结构。

\section{5.销售渠道货币化现象案例与分析}

\section{1 销售渠道货币化现象案例}

金乡县隶属于山东省济宁市, 地处我国东部的鲁
西南平原腹地, 县域面积为 886 平方公里, 全县辖 9 个镇, 户籍人口 67.3 万人, 地面高程在海拔 34- 40 米之间, 属暖温带季风大陆性气候, 具有冬夏季风气 候特点, 适宜葡萄种植。目前, 全县葡萄种植面积达 到一万余亩, 品种包括青提、红提、早熟 612、藤稔、 巨峰、玫瑰香、乒乓球等品种。

2008 年以来, 金乡县 9 个乡镇先后成立葡萄合作 社 35 家, 主要由农民发起, 以村为基本单元。合作 社主要负责组织采购成员种植葡萄所需的资料, 组织 销售成员种植的葡萄, 开展与种植葡萄有关的技术咨 询服务。由于葡萄种植季节性强、成熟期集中上市、 采摘后保鲜期短等原因, 种植规模扩张带来的市场风 险比较突出, 主要体现在销售渠道的相对稀缺性与信 息不完全带来的销售摩擦力。根据实地调研, 销售渠 道更多的为村内个人所掌握, 而非合作社自身。究其 原因主要包括两个方面: 一是客商主要来自周边地市, 对当地葡萄种植的基本情况（种植品种、种植农户、 葡萄质量等）并不了解，存在信息不对称的问题，具 有在当地寻找代理人的需求; 二是由于客商在葡萄批 发采购过程中存在隔夜住宿和用餐需求，而与进城食 宿相比, 代理人可以高效率、低成本解决上述问题。

从资源禀赋的角度来看, 由于年龄、社交经验、 外拓渠道等现实差异导致葡萄种植大户、能户拥有丰 富的销售渠道，而普通种植户缺乏销售渠道。在销售 渠道流转与优化配置过程中逐渐出现了有偿使用现 象（无销售渠道的社员通过其他社员的销售渠道卖葡 萄, 被收取手续费 0.1 元/斤, 每亩产量 6000 斤左右, 为此每亩的成本约 600 元), 较高的葡萄批发价格 (平 均 4-5 元）支撑了这种交易。对于这种将自己的掌握 的销售渠道让渡给他人使用并按销售数量收取使用 者手续费的现象，我们定义为销售渠道货币化。

\section{2 销售渠道货币化现象分析}

上述案例中，销售渠道货币化现象产生的原因主 要包括两个方面。第一，农民专业合作社在初步发展 阶段，尽管现有国家层面的法律制度保障，但在协调 内部社员资源禀赋差异方面先天不足。在其内部的规 章制度与规则中，无法直接体现对销售渠道资源丰富 的社员的激励机制，这导致仅仅是人层面的入社，在 抽象的销售渠道层面并未入社。伴随着不同主体（合 作社、管理者、渠道丰富的社员、普通社员）之间的 妥协与达成的默契，销售渠道以货币化的方式进行了 高效流转和配置。销售渠道货币化是组织演进过程中 合作社异化诱发的均衡发生漂移的结果，是销售资源 富足者对合作社“选择性激励”力量不足的应激性反 应, 也是普通社员面临市场风险袭扰的最优选择。第 二，除过前面订单农业方式，销售渠道货币化是解决 市场风险问题的具体方式之一，远比塑造品牌这种抽 象方式更可感知与可控。这种非正式制度刺激了更多 的合作社成员去寻找更广范围的销售渠道。它实质上 是合作社销售渠道职能萎缩所带来的职责外包转嫁 问题。在当前合作社发展不均衡与市场发育不健全的 
背景下, 销售渠道货币化可以很好的解决激励不足问 题, 短期内看, 这种双赢的、过渡性的资源配置与优 化的非正式制度安排不失为明智的选择。

当然, 从长远发展的角度看, 销售渠道货币化是 一种福利的损失, 这种多余的成本更多得为弱势群体 所承担, 它与合作社扶贫救弱的基本精神相违背, 且 与合作社的制度内核与质性规定相冲突, 最终需要从 根本上予以解决。但短期内, 它激励了具有相应资源 禀赋的成员主动提供相应的销售渠道, 整体上降低了 合作社的市场风险, 增进合作社总体福利。

\section{6. 结论}

从销售渠道货币化的交易关系中，折射出的是农 民专业合作社发展困境的一个缩影。卖方市场向买方 市场转变的背后往往伴随着农产品供给的迅速扩张。 销售渠道作为一种相对稀缺资源, 在经济货币化的环 境里也迅速实现着自身的货币化进程。通过对 35 个 葡萄农民专业合作社的调查与分析, 从短期和长期两 种时间维度可以清晰地得到如下结论。

第一, 从国家宏观层面, 除了法律供给与制度供 给之外, 更需要建立起统一性的组织及时发布农产品 供求信息与销售渠道服务, 减少由于信息不完全与信 息不对称带来的销售摩擦力, 促进区域之间资源整合 与优化配置。同时, 加强农业基础设施建设与维护, 为产业的发展提供良好的配套环境。

第二, 在部分农产品 (如葡萄)生产销售过程中, 可由合作社层面组织并实施销售渠道货币化机制, 鼓 励社员做大整体福利, 同时促进内部福利的二次转移。 对政府而言, 可以将补贴销售渠道货币化的手续费为 着力点, 由其出资帮扶农产品种植中的弱势群体, 提 升涉农资金使用的效率和针对性。
第三, 在美丽乡村建设的背景下, 根据销售渠道 丰富者撮合成交的农产品交易数量, 可由地方政府向 无偿为普通社员提供销售渠道的人员分层级授予不 同的荣誉, 进而从长期的制度安排中实现“荣誉置换 物质 (手续费) ”的激励相容机制。

\section{REFERENCES}

[1] Xu Jian, Wang Xuhui. An Empirical Analysis of the Impact of Contract Agriculture and Its Organization Mode on Farmers' Income [J]. China Rural Economy, 2009(04): 39-47.

[2] Tian Yiwen, Zhang Qi, Xu Kun. The development of farmers' professional cooperatives and market risk analysis from the perspective of law: Taking Yangling Agricultural Demonstration Zone as an example [J]. New West, 2010(01): 92-93+90.

[3] Liu Ke. Analysis of the ways to avoid risks in the agricultural product market in my countryBased on the perspective of farmers' professional cooperatives[J]. Henan Agriculture, 2013(20): 1113.

[4] Chen Jianghua, Li Daohe, Sun Shui'e, Kang Xiaolan. Influencing factors of members of farmers' professional cooperatives in Jiangxi Province participating in cooperative contract agriculture[J]. Guizhou Agricultural Sciences, 2014, 42(12): 243-248.

[5] Xiao Yaqian. Research on Risk Assessment and Prevention of Farmers' Professional Cooperatives in Heilongjiang Province [D]. Northeast Agricultural University, 2018. 